\title{
Ethiopian Early Grade Mathematics Curriculum Organization
}

\author{
Aynalem Tesfaye $^{1} \quad$ Kassa Michael $(\mathrm{PhD})^{2}$ \\ 1.PhD Candidate at Addis Ababa University, Science and Mathematics Education Department, and Teacher \\ Educator at Hawassa College of Teacher Education \\ 2.Department of Science and Mathematics Education, Addis Ababa University
}

\begin{abstract}
Early grade education is basic and necessary for preparing students for their future education and life. Therefore, paying attention for early grade mathematics education has a multidirectional contribution to the quality of education in a country. This study investigated Ethiopian early grade mathematics curriculum organization in relation to its responsiveness to children learning progression. In this study a qualitative research approach was employed. 4 early grade mathematics teachers participated in evaluating the early grade mathematics curriculum (minimum learning competency (MLC) document, syllabus, and flowchart document). In addition, two educational experts at the regional education bureau and the Ministry of Education (MoE) participated in the study. The data were collected through interview and document analysis by using content analysis protocol developed by adapting the national guideline for preparing and evaluating teaching-learning materials (Taye, 2011), mathematics content analysis (Aggarwal, 2009; Hashmi, Hussain, \& Shoaib, 2018), and learning progression responsive curriculum (Bristow \& Patrick, 2014; Council, 2007; Duschl, Maeng, \& Sezen, 2011; Popham, 2007; Sáez, Lai, \& Tindal, 2013; Simon, 1995; Wilson \& Bertenthal, 2005). The study revealed that there are considerable gaps in the early grade mathematics curriculum in relation to responding to children learning progression at the level. The study recommends special focus to be given for children learning progression and alignment of curricular materials when developing early grade mathematics curriculum. The study further suggested developing a learning progression document, based on research evidence that can be used as a guide for the textbook and other curricular materials development.
\end{abstract}

Keywords: Curriculum organization, Early grade mathematics, Learning progression

DOI: $10.7176 / J E P / 12-25-03$

Publication date:September $30^{\text {th }} 2021$

\section{Introduction}

Organization of a curriculum is central for effective execution of the curriculum, and scope and sequence are core elements in it as they help to understand children's development in learning and to scaffold accordingly (Davis et al., 2017). Evaluating the organization and alignment of contents in curriculum materials provide valuable evidence on the appropriateness of the structure of contents and their adequacy in the given materials. As the students advance from grade to grade, it is expected that they understand more about the world and about themselves, and this can be supported by a curriculum which is organized by considering students' learning progression at the level. In different countries like China, Australia, Canada, New Zealand, Korea, and Singapore, learning progression serves as a backbone of content area achievement standards of their respective country. Therefore, learning progression is an important concept that has to be considered in developing curricular materials at any level of education because it can inform content selection and their flowchart, techniques of teaching and learning, and level-appropriate assessment (Sáez et al., 2013).

Mathematics is a discipline in which ideas (starting from elementary concepts) are sequenced and interrelated. Students can understand the mathematical concepts at their level if they are familiar with the basic ideas that are related to the concept. The early grade is a foundational level for children's future success; hence, the idea of learning progression is necessary for effective mathematics learning at the level. Learning progressions describe what it means to move towards more expert understanding in an area and measure students' increased competence with a core concept or a scientific practice. Consciously developed and properly tracked learning progression is believed to enforce better learning achievement and success of children in their learning. Practice in Ethiopia, however, is described by lower student academic achievement, that by contraposition raises issue of the curricular organization. This study is, therefore, made to explore the Ethiopian early grade curriculum organization and forward inputs for further elaborations of the curriculum and reform.

\section{Learning Progression and Curriculum}

2.1. Learning Progression

Learning progression has got attention from scholars and educators nowadays as it has multi-purpose accounts in

\footnotetext{
${ }^{1} \mathrm{PhD}$ Candidate at Addis Ababa University, Science and Mathematics Education Department, and Teacher Educator at Hawassa College of Teacher Education

${ }^{2}$ Department of Science and Mathematics Education, Addis Ababa University
} 
the educational system. It focuses on sequencing of teaching and learning expectations across different developmental stages, ages, or grade levels. In the pool of literatures we found different explanations about learning progression. Wilson and Bertenthal (2005) expressed learning progression as a description of what students are expected to learn and how that learning happens as the student progresses through the instructional material. According to Council (2007), learning progressions is a description of increasingly sophisticated ways of thinking about or understanding a topic, and Popham (2007) state it as a set of a carefully structured set of building blocks that students must master in order to control the objectives of the curriculum. From these, learning progression can be considered as a description of an increasing level of difficulty and complexity of contents, and associated teaching and learning to acquire knowledge, skills, and attitudes within a domain.

According to Sáez et al. (2013), learning progression consists of a series of the successive and more complex ways of thinking about an idea that might reasonably follow one another in the process of students developing understanding about that idea. This indicates that contents in learning progressive mathematics curricular materials need to be presented through proper sequencing and in a way that the students can understand them easily and to have more advanced knowledge on it. That means contents in a given curricular materials have to be presented in a way that it shows learning progression that can lead the students for effective learning and the teacher to teach the concept effectively. Simon (1995) puts that learning progression in mathematics has to include; the learning goal, the learning activities and the thinking and learning in which student might engage. Therefore, effective learning needs a description of decisive sequencing of learning expectations to be followed during learning. And hence, learning progression has to base on children's pre-requisite knowledge, nature of mathematics, level of complexity, and the sequence of contents.

\subsection{Competency Based Curriculum and Learning Progression}

In Ethiopia curriculum is designed to be a competency-based. In this sense, the focus of learning is on children's ability to demonstrate their competency. In Ethiopia, competency is operationalized as an integrated set of skills, knowledge, and attitudes that enables one to effectively perform the activities of a given expected standards (MoE, 2009). To reach to the level, and track the means learning progression is important, and learning progression is a core idea in competency-based learning (Bristow \& Patrick, 2014). Core tenets of competency-based learning need clear articulation of learning goals, credit for mastery, and anytime/anywhere learning (Steele et al., 2014). This indicates the essentiality of a curriculum that is organized to be responsive to learning progression and that enables the student to have deep understanding of the concepts there. In a learning progression responsive curriculum, it is expected that concepts are built based on logical and successive approach, presented in an appropriate way for students at the level and in a way that ideas are connected to enable the students to understand the concept easily (Sáez et al., 2013).

\subsection{Importance of Considering Learning Progression during Curriculum Organization}

Considering learning progression when developing mathematics curricular materials has many advantages in assuring children effective learning of mathematics. Scholars put different merits of considering students learning progression in a curriculum. Wilson and Bertenthal (2005) point out that learning progression contributes for the development of advanced understanding to the concept, hence it serves as a target for curriculum, instruction, and assessment. The coherence of learning progression across grade level enables students to develop the understanding of the concept and the teacher to decide the mastery level of students in the given concept (Bristow $\&$ Patrick, 2014). These further show the necessity of focusing on students learning progression when developing teaching-learning materials. Moreover, Wiser, Smith, and Doubler (2012) underlined that a given curriculum has to be presented in a way that it reflects learning progression of the given concepts clearly. This allows not only students but also teachers to think about the current state of learning and to make pedagogical decisions to develop what they will learn in the future. Learning progression responsive curriculum focuses on students' understanding and indicates the place where misunderstanding can occur, steps that are necessary for mastery, and allow the teachers to teach accordingly (Sáez et al., 2013). Therefore, developing curricula and curricular materials by considering students' learning progression enables a teacher to perform what is expected to the level, and use appropriate assessment by clearly indicating key concepts (Wiser et al., 2012), and the learners build their deeper understanding. Accordingly, Wiser et al. (2012) suggest that the curriculum should not only enrich students' knowledge but also focus on structure to help the students develop the right ideas at the proper level and in a scientific way.

\section{Research Problem}

A lot has been done to improve the quality of education in Ethiopia. However, quality is still an issue in the education system, especially at the early grade levels. Studies disclosed that in early grade mathematics children showed discouraging results in capturing advanced concepts and conceptual knowledge at their level (Aynalem, Nigusse, \& Kassa, 2020; NEAEA, 2014, 2018, 2019). Moreover, in the fifth national learning assessment report 
of grades 4 and 8 students, it was stated that students' performance in mathematics was becoming lower when they go to the next higher grades (NEAEA, 2016). In association with these various background profiles and categories that could contribute to the low academic achievement were explained, but curriculum related studies. Quality of curricular materials is one of the main contributing factors of students learning (Hashmi et al., 2018; Okeeffe, 2013; Sunday \& Adebowale, 2013), however, studies that focus on the quality and fairness of contents in the Ethiopian early grade mathematics curricular materials are rare.

Currently, curriculum revision process is started for all levels of schools and subjects based on the Ethiopian Education Development Roadmap (EEDR), 2018. However, the EEDR is a holistic document that shows the overall result expected from the education system with targets and indicators. Hence, it is difficult to maintain the expected quality in the reformed curriculum without considering researched evidences that are related to the subject area and level, as each discipline has its own characteristics and each level has its own context. Therefore, this study aimed at examining the early grade mathematics curriculum to see whether contents in it are organized by considering children learning progression. This can contribute more for the development of quality early grade mathematics curriculum by providing valuable information concerning the appropriateness, adequacy, and logical sequencing of mathematics contents at the early grade levels.

\section{Research Questions}

The objective of this study was to examine the organization of the early grade (grades 1 - 4) mathematics curriculum in order to see to what extent the curriculum responds to children learning progression. Based on this, the following research questions were formulated.

- Are the contents in the curriculum sequenced logically, connected, and continuous across topics and grade levels?

- Are the contents in the early grade mathematics curriculum presented and discussed by considering children's individual, social, and cultural conditions?

- To what extent are the contents in the early grade mathematics curriculum adequate to equip children with the necessary knowledge and skills at the level?

- How should the curriculum be organized to ensure learner progression?

\section{Methods}

This study explored the organization of the Ethiopian early grade mathematics curriculum based on its responsiveness to children learning progression using a qualitative research approach. In this study, early grade mathematic curriculum (MLC document, syllabus, and flowchart document) and associated student texts and teacher guides were focused. Four early grade mathematics teachers at Halaba Zone of Southern Nations and Nationalities Peoples Regional State (SNNPRs) participated in reviewing the materials. The teachers were selected purposely based on their teaching experience and efficiency in teaching early grade mathematics. In addition, two curriculum experts at the SNNPRS education bureau and MoE were interviewed to document their views on the organization of early grade mathematics curriculum as they are the main stakeholders in coordinating and supervising educational activities in the region as well as in the country respectively. Data were collected through interview and document analysis by using content analysis protocol. The content analysis protocol was developed by adapting the national guideline for preparing and evaluating teaching-learning materials (Taye, 2011), other works on mathematics content analysis (Aggarwal, 2009; Hashmi et al., 2018), and learning progression responsive curriculum (Bristow \& Patrick, 2014; Council, 2007; Duschl et al., 2011; Popham, 2007; Sáez et al., 2013; Simon, 1995; Wilson \& Bertenthal, 2005). The protocol was further reviewed for face and content validity by two curriculum and assessment experts. As recipe the protocol was tested by implementing it to conduct analysis of a single unit by two scholars and the extent of homogeneity of responses was ensured that validates the use of the protocol. The four mathematics teachers were oriented with the protocol and made to practice on the unit the protocol was employed on to assure that these teachers can conduct the content analysis. After ensuring their preparedness the teachers were made to analyze the early grade mathematics curriculum for data collection. The collected data were analyzed thematically where the core themes were structure and alignment; logical arrangement of contents, continuity and connectedness; appropriateness of contents; and adequacy of contents.

\section{Findings and Discussion}

The organization and presentation of contents in a given curriculum determine the effectiveness of implementation of the curriculum (Gagné, Scriven, \& Tyler, 1969). If there is proper curriculum organization aligned to children learning progression that maintains the depth and breadth of the contents of the subject matter then it is believed to be critically powerful to meet standards. Therefore, this study focusing on early grade mathematics curriculum of Ethiopia saw the organization and presentation of contents and whether these respond to children learning progression. Accordingly, the findings are presented addressing the following themes: (1) the structure and alignment of contents, (2) logical arrangement of contents, continuity and connectedness of concepts among topics 
and grade levels, (3) appropriateness of contents in relation to the nature of mathematics and children context, and (4) adequacy of contents in the curriculum to equip early grade children with the necessary knowledge and skills, and whether they help to attain the learning objectives at the level.

\subsection{The Structure and Alignment of Contents}

To build the capacity of each student, a well-structured mathematics curriculum is substantial (Hilario, 2006). The Ethiopian early grade mathematics curriculum is organized around four major strands (numbers \& operations, measurements, geometry, and statistics (data handling)). These strands are presented in the curricular materials: syllabus, MLC document, and document in different forms. Containing well-structured and appropriately presented contents is one of the important features for learning progression responsive curriculum (Sáez et al., 2013). As the findings shown the strand 'Number and operation' contains the contents; whole numbers, fractions, decimals, and basic operations (addition, subtraction, multiplication, \& division of whole numbers). Measurement strand covers the contents; length, weight, capacity, time \& money. Under Geometry strand early grade children are expected to learn about; shapes \& solid objects, and the Statistics strand focus on patterns and graphs. Contents in a curriculum have to be structured in a way that enables students to have the expected mastery level in the given content at their level (Hilario, 2006; Popham, 2007). Even if the structure of contents seems well, the findings show that there are gaps in structuring some topics by considering the complexity level of concepts at each grade level and consistently through grade levels, especially fraction, measurement, and geometry concepts. Table 1 show the structure of contents under each strand at each early grade level and it is extracted from the early grade mathematics curriculum.

Table 1: Contents Under Each Strand of Each Early Grade Level

\begin{tabular}{|c|c|c|c|c|}
\hline Strands & Grade 1 & Grade 2 & Grade 3 & Grade 4 \\
\hline 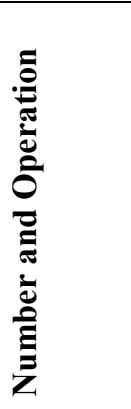 & $\begin{array}{l}\text { - Whole } \\
\text { numbers up } \\
\text { to } 100 \text { and } \\
\text { operation } \\
\text { with these } \\
\text { numbers } \\
\text { - Fractions } \\
\text { (haves and } \\
\text { quarters) }\end{array}$ & $\begin{array}{l}\text { - Numbers up to } 1000 \\
\text { and operation with } \\
\text { these numbers } \\
\text { - Fractions (thirds, and } \\
\text { wholes and parts) }\end{array}$ & $\begin{array}{l}\text { - Numbers up to } 10,000 \\
\text { and operation with } \\
\text { these numbers } \\
\text { - Fractions (unit } \\
\text { fractions from } 1 / 2 \text { to } \\
1 / 10 \text {, half and quarter } \\
\text { of whole numbers) } \\
\text { and comparison of } \\
\text { simple fractions }\end{array}$ & $\begin{array}{lr}\text { - Numbers up } & \text { to } \\
1,000,000 & \text { and } \\
\text { operations with } & \text { wer numbers } \\
\text { these nus } \\
\text { - Fractions and } \\
\text { operation on } \\
\text { fractions with the } \\
\text { same denominator } \\
\text { - Tenths, hundredths, } \\
\text { and decimals }\end{array}$ \\
\hline 莺 & $\begin{array}{l}\text { - Measuremen } \\
\text { t using non } \\
\text { formal units } \\
\text { (length, } \\
\text { capacity, and } \\
\text { weight) } \\
\text { - Time (time } \\
\text { of the day, } \\
\text { and days of } \\
\text { the week, } \\
\text { time in hours } \\
\text { in analog } \\
\text { clock) } \\
\text { - Money } \\
\text { (Ethiopians } \\
\text { coins and } \\
\text { notes, and } \\
\text { their } \\
\text { relationship) }\end{array}$ & $\begin{array}{l}\text { - Measurement (length } \\
\text { in cm and m, capacity } \\
\text { in } 1 \text {, and weight in kg) } \\
\text { - Time (time in hours } \\
\text { and minutes, } 1 / 2 \text { hours } \\
\text { and } 1 / 4 \text { hours in } \\
\text { analogue and digital } \\
\text { clock) } \\
\text { - Money (Addition and } \\
\text { subtraction of money } \\
\text { using Ethiopian } \\
\text { currency) }\end{array}$ & $\begin{array}{l}\text { - Measurement (length } \\
\text { in mm, cm, m, and } \\
\mathrm{km} \text {, capacity in ml } \\
\text { and } 1 \text {, and weight in g, } \\
\text { kg and quintal) } \\
\text { - Time (reading clocks, } \\
\text { days, weeks, months, } \\
\text { and years, and simple } \\
\text { calendar) } \\
\text { - Money (Conversion } \\
\text { of units of money) }\end{array}$ & $\begin{array}{l}\text {-Measurement (length } \\
\text { in mm, } \mathrm{cm}, \mathrm{m} \text {, and } \mathrm{km} \text {, } \\
\text { capacity in } \mathrm{ml} \text { and } 1 \text {, } \\
\text { and weight in } \mathrm{g}, \mathrm{kg} \text {, } \\
\text { quintal, and tone) and } \\
\text { converting one unit of } \\
\text { measurement in to the } \\
\text { other seconds, } \\
\text {-Time (hours, minutes } \\
\text { and time, and } \\
\text { calculation with units } \\
\text { of time } \\
\text { comparison of time } \\
\text { measurement) }\end{array}$ \\
\hline 芯 & $\begin{array}{l}\text {-Straight and } \\
\text { curved lines } \\
\text {-Rectangles, } \\
\text { triangles, and } \\
\text { circles }\end{array}$ & $\begin{array}{l}\text {-Points, and lines } \\
\text {-Squares, rectangles, } \\
\text { triangles, and circles } \\
\text {-Shapes in the } \\
\text { environment }\end{array}$ & $\begin{array}{l}\text {-Intersecting, parallel, } \\
\text { and perpendicular lines, } \\
\text { and constructing them. } \\
\text {-Rectangle, square, } \\
\text { parallelogram, } \\
\text { trapezium, and circle }\end{array}$ & $\begin{array}{l}\text {-The right angle } \\
\text {-Perimeter and area of } \\
\text { rectangles and squares } \\
\text {-Simple solids }\end{array}$ \\
\hline
\end{tabular}




\begin{tabular}{lllll}
\hline Strands & Grade 1 & Grade 2 & Grade 3 & Grade 4 \\
\hline & -Simple picture & -Collection of simple & -Simple picture graphs & -Construction of \\
& graphs & data & -Interpretation of simple & simple bar graphs for a \\
& -Simple & Table of simple data & picture graphs & collected data \\
& patterns & Simple pattern of & -Interpretation of bar \\
& & numbers and shapes & & graphs \\
& & & & -Average up to four \\
& & & & numbers
\end{tabular}

The findings further show that there is a problem of alignment among curricular materials but, the alignment of curricular materials contributes to the achievement of educational objectives (Ornstein, 1994). This may be due to the reason that there is no well-prepared learning progression document that can be used as a guide for curricular material preparation. While curriculum framework presents content structure across units and grades, the depth and breadth, and the expectations from students at each level needs to center at the children learning progression. This indicates the need for developing a separate document that can clearly indicate children learning progression in mathematics that can be considered for learning mathematics and used as a guide for developing other curricular materials. The following extracts are taken from the analysis of the review of early grade mathematics MLC document, syllabus and flowchart documents.

Table 2. Strands and corresponding topics in the Early Grade Mathematics Curricular Materials

\begin{tabular}{ll}
\hline Document & Strands and their corresponding topics \\
\hline MLC document (grade1-4) & - Numbers: whole numbers, fractions \& decimals \\
& - Addition, Subtraction, Multiplication \& Division of numbers \\
& - Measurements: Length, weight (mass) \& capacity \\
& - Geometric shapes \& solid objects \\
& - Money \\
& - Time \\
& - Patterns \& Graphs \\
- Numbers \& Operations: whole numbers, fraction \& decimals & - Measurement: Length, weight, capacity (grade 3 \& grade 4) \\
- Geometry: lines, shapes and solids \\
- Money \\
- Time \\
- Data handling and pattern \\
- Number Systems and Arithmetic Operations: Natural, whole numbers \& \\
- rational numbers \\
- Measurement: length, capacity, weight \\
- Mometry: time, geometric shapes and solid objects \\
- Statistics: Data Handling \& Patterns /Graphs
\end{tabular}

\subsection{Logical Arrangement and Continuity of Contents}

Studies recommend that contents in a curriculum has to be arranged in a way that the order of contents is from simple to complex, spiral, whole to part, and responsive of children prerequisite learning, real-life condition, and order of events (Bayissa, 2000; Bruner, 2009; Ornstein \& Hunkins, 1998; Print, 1993). Moreover, learning progression responsive curriculum shows the connection among units, topics, subtopics, and concepts clearly (Wiser et al., 2012). The findings of the analysis of the evaluation indicated that some of the contents under the given topics in each grade level and across the grade levels are inconsistent and lack logical order in terms of children's level of understanding and the nature of mathematics. It is suggested that contents in the curricular materials to be presented clearly and consistently through the topics and grade levels (Taye, 2011). However, contents under measurement strand were not presented consistently through the grade levels. For instance; in the syllabus and flowchart document, contents under measurement were sequenced as; length, capacity \& weight for grade 1 and grade 2, and length, weight, and capacity for grade 3 and grade 4 . In the MLC document the content sequenced as length, weight (mass), and capacity. Organization of contents in a curriculum should preserve the nature/logic of the subject matter and psychological rules of learning (Hunkins \& Ornstein, 2016; Talla, 2012). However, the organization of some contents showed gaps in considering these basics. For instance; from grade 13 fraction concept was discussed before treating the concept of operations of numbers up to the specified whole 
numbers at the grade level and after the concept of measurement, but in grade 4 it was treated before the concept of measurement and after discussing operation on numbers up to 1,000,000. Some repetitive presentation was also observed in grades 3 and 4 . These show the problem of coherence and consistency of contents in the curricular materials. This may have negative influence on early grade children learning of the concepts effectively.

The findings further showed that some competencies are disordered in the MLC document as well as in the syllabus. For example; in grade 1 MLC document students are expected to develop the competency in "multiplication and division of whole numbers by 2 " before the competency "identify the symbols, $\mathrm{x}$ and $\div$ ". In the corresponding syllabus it is suggested to teach the concept of multiplication and division of whole numbers by using objects and pictures, and expressing the concept numerically by using the syllabus $\mathrm{x}$ and $\div$. Of course, it is logical to explain multiplication and division concepts by using different objects and ideas for which children are familiar. After that it is possible to relate the symbols with the concepts. However, using symbols to multiply and divide before explaining the relationship between the symbols and the concepts of multiplication and division that the children were introduced, is not helpful to enable children to understand the concepts.

In the syllabus and MLC document some competencies are disordered, for instance; in grade 1 for multiplication and division concept, competencies are listed illogically, because without introducing children about the symbols of multiplication and division adequately it is not reasonable to expect children to multiply and divide whole numbers using the symbols.

Not only was this but also the findings indicated that the topics fraction and measurement are placed inappropriately and inconsistently in the curriculum. For instance, in grade 1 syllabus the topics "measurement and fraction" were treated before treating reading, writing, ordering, comparing, and operating whole numbers 21 - 100. Measurement involves expressing the amount of objects or items by using numbers (Clements \& Stephan, 2004) and hence early grade children need to learn numbers $21-100$ before learning the concepts in measurement strand. Especially, the concept of fraction involves not only the knowledge of numbers but also geometric shapes as the suggested learning experience indicated in the corresponding syllabus.

The topics "measurement and fraction", are inappropriately located because it is not fair to discuss fraction and measurement before completing reading, writing, and counting numbers up to 100.

Also, in measurement strands across grade level contents the organization lacked logical sequence in relation to the complexity of contents across the grade levels. In grade 1, children learn time of the day, days of the week, and reading time from analogue clock. But reading time could not worth before learning minute and second from analog clock as it contains minute and seconds counter (pointer). This may cause cognitive load to children.

Table 3. Contents Suggested for Learning Early Grade Time Measurement

\begin{tabular}{|c|c|c|c|c|}
\hline & Grade 1 & Grade 2 & Grade 3 & Grade 4 \\
\hline \multirow{4}{*}{ 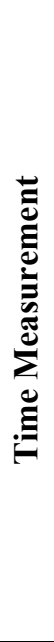 } & $\begin{array}{l}\text { - describe events of } \\
\text { their lives according } \\
\text { to the time of day }\end{array}$ & $\begin{array}{l}\text { - tell the time in hours, } \\
\text { half hours and quarter } \\
\text { hours using an } \\
\text { analogue and a digital } \\
\text { clock }\end{array}$ & $\begin{array}{l}\text { - describe the relationship } \\
\text { between hour and } \\
\text { minutes }\end{array}$ & $\begin{array}{l}\text { - } \text { describe the } \\
\text { relationship } \\
\text { between hours, } \\
\text { minutes and } \\
\text { seconds }\end{array}$ \\
\hline & $\begin{array}{l}\text { - morning, afternoon } \\
\text { and evening }\end{array}$ & $\begin{array}{l}\text { describe the relation } \\
\text { between hours and } \\
\text { minutes }\end{array}$ & $\begin{array}{l}\text { - read an analogue and a } \\
\text { digital clock in hours, } \\
\text { minutes }\end{array}$ & $\begin{array}{l}\text { - convert units of } \\
\text { time }\end{array}$ \\
\hline & $\begin{array}{l}\text { - name the days of the } \\
\text { week }\end{array}$ & & $\begin{array}{l}\text { - relate days, weeks, } \\
\text { months and years }\end{array}$ & $\begin{array}{l}\text { - compare units of } \\
\text { time. }\end{array}$ \\
\hline & $\begin{array}{l}\text { - tell time in hours } \\
\text { from an analogue } \\
\text { clock }\end{array}$ & & - read a simple calendar & \\
\hline
\end{tabular}

These show that there is a lack of logical organization and presentation of contents in the curriculum. It also shows that there is a problem of connectedness and continuity of contents through different units and grade levels.

The Curriculum Framework for Ethiopian Education ( $\mathrm{KG}$ - Grade 12) (MoE, 2009) suggest the spiral approach for structuring and presenting contents. Following the spiral approach to present contents in the curriculum helps to ensure children understanding of full concepts in the topic (Rhalmi, 2011). It also helps to keep logical arrangement of concepts, from familiar/simple to new/complicated ideas, and considering prior knowledge and building new learning on it. However, the aforementioned findings indicate that contents in early grade curriculum are not arranged in logical order, and hence may not be fully responsive of children conditions and the nature of mathematics. Hence, in the curriculum the spiral approach has not been fully considered even if the contents treated in each grade level seems to be presented in hierarchical order. The curriculum framework specifies number system is introduced step by step and the ability of students to order and perform fundamental 
operations on numbers. In this regard most of the main topics in the curriculum are presented in logical order (for instance; numbers up to 100 for grade 1, up to 1000 for grade 2, up to 10,000 for grade 3 , and up to $1,000,000$ for grade 4), but the specific contents and the expected competencies within are not presented in sequential and progressive order. Therefore, the evidences lead us to conclude that less attempt was done during curriculum preparation to connect learning concepts and show learning progression. This issue was also mentioned in Abraha (2015) dissertation paper that the progression in terms of competencies is not clearly indicated in MLC document. This may influence the development of quality textbooks, the TL process, and the attainment of learning objectives.

\subsection{Appropriateness of Contents}

In learning progression responsive curriculum, it is expected that the sequence of contents be appropriate for students' developmental stage, age, and grade level. In addition, contents in a given curriculum is said to be appropriate if it is presented by considering the sense; from simple to complex, spiral, whole to part, children experience and real life condition, and order of events (Bermejo, Ester, \& Morales, 2021; Sáez et al., 2013). The findings from this study indicated that the presentation of contents in early grade mathematics curriculum lacked appropriateness in relation to these lucidities.

Stating learning experience in the syllabus helps to improve children development in their learning (Hyson, 2016). However, the findings show that learning experiences in the syllabuses are not appropriately and clearly described and some of the stated experiences are not children context responsive. As an example, presentation of instructional experiences, for the concept of fraction, in the grade 1 syllabus is not appropriate. The grade 1 syllabus suggests teachers to provide different shapes and encourage students to show, draw and cut shapes in teaching the concept of fraction, but children are not well familiar with the name and properties of shapes at the level as most Ethiopian children start their education at grade 1. The order was also that fraction precedes shapes. Also, the concept of fraction is related with the concept of division and hence it may not help children at the level to get clear understanding about fractions, despite the possibility of considering these as parts of a whole. The evaluators stated in their report from their experience of teaching mathematics at early grades that their students in grade 1 faced difficulties when they learnt the concept of fractions. This may be due to the content structured and presented in the curriculum without considering children context, especially children experience, cognitive level and familiarity with the contents. The results further showed that some contents in grades $1 \& 2$ are dense and contain some inappropriate concepts to the level. The abstract nature of fractions may also be point of contention whether that could be offered as early as grade 1 . These may also cause ineffective organization and delivery during TL process and children poor performance in learning mathematics.

\subsection{Adequacy of Contents}

Presenting contents adequately in the given curriculum is necessary for effective implementation of the curriculum and hence to enable students to have adequate knowledge and skills which are expected at the level. The education and training policy document of Ethiopia suggests early grade children to have deep understanding of number concept and the ability in using mental and written strategies for solving problems (TGE, 1994). This shows early grade mathematics curriculum contents to be adequately presented in order to enable children to be in the expected level. Therefore, it is possible to say the contents presented in different components of the curriculum are adequate if they are helpful to equip children with the necessary knowledge and skills expected at the level. However, the findings demonstrate that contents in the early grade mathematics curriculum lack adequacy to help the children understand the concepts and apply them in problem solving. To mention some; in the MLC document and syllabus, children feeling and attitude were not focused on the specified learning objectives but they are necessary for children's effective learning of mathematics. Children's attitude in learning mathematics contributes to their performance in mathematics learning, hence not giving the required attention to children feeling and attitude may influence children learning (Kasimbu, 2004) and this may cause negative outcome in their learning. Although the concept of the relative position of numbers is very important for children to have a deep understanding of the concept and application of numbers, the findings show that the concept of the relative position of numbers is not discussed in the early grade mathematics curriculum. The claims about inadequacy of contents in the curriculum were also mentioned by the interviewed educational experts at SNNPRS and MoE. According to the interviewees, the organization of early grade mathematics curriculum lacks some features which are imperative for early grade children mathematics learning. The interviewees underlined those contents which were presented in the curriculum are good but some contents are forgotten and the presented contents are even not adequately expressed and not organized well.

Reasoning is a basic skill that leads children to expert understanding of a given content. A child who is able to justify her/his understanding of the rules in mathematics can have a better opportunity in performing less familiar tasks that are related to the rule (Initiative, n.d). NCTM for learning mathematics also mentioned reasoning as one of the main goals of learning mathematics (NCTM, 2000). However, the findings show that less focus was given in early grade mathematics MLC document and syllabus for reasoning skills. This may cause giving less attention 
for the reasoning skill when presenting contents in the corresponding curricular materials; like textbooks and teachers guide since MLC document and syllabus are guides for developing them. These may also cause learning mere facts without producing reasons for what happens. The results further showed that the competencies in the MLC document under the topic "fraction" and in grade 4 syllabus the unit outcomes under the topic "operations on whole numbers up to 1,000,000" are not adequately discussed. In addition to that, the findings showed that in the MLC document competencies that explain about the application of concepts of a given content in real-life activities are rare. This may contribute for children poor understanding about the application of mathematical concept in their day-to-day life that could have helped them develop appreciation, and link the learning with possible reasons.

Approaches to learning competencies play an important role in children's development (Hyson, 2016), though the results show that the learning experience in the syllabuses express more about activities but not about approach how these activities can be executed. That is, in the syllabus the main focus was not on how to do rather what to do. These show that the content presentation in the curriculum focus more on procedural fluency than conceptual understanding. Hence, it is difficult to identify the skills expected to be developed by children in the given concept, because instructional approaches determine children learning in developing different skills like reasoning, writing, thinking, applying, communicating, using, etc.

In general, the above discussion leads to the concussion that even if most of the necessary contents are discussed in different components of the curriculum some of the contents were not adequately elaborated and some of the important contents were missed. Hence, contents in early grade mathematics curriculum lack adequacy to equip children with the necessary knowledge and skills at the level.

\section{Conclusion}

The quality of curriculum determines the effectiveness of the implementation and contribute more for the attainment of 2030 agenda, SDG4 by providing guide for the delivery of quality instruction (Stabback, 2016). Hence, a curriculum that is well organized and clearly shows children learning progression helps to develop quality instructional materials, like textbooks and teachers guide. It also enables the teachers to teach with good understanding of children learning progress in a given concept, and students to learn effectively and to have deep understanding about the concepts. Therefore, the findings and discussions in the above led the following concluding notes.

1. In early grade mathematics curriculum, gaps were observed in organizing contents in a way that it shows connection of concepts among topics and grade levels, responsiveness of the nature of mathematics and children's context, and consideration of children's individual, social, and cultural conditions.

The early grade mathematics in Ethiopia is organized in four major strands; numbers \& operations, measurements, geometry, and statistics (data handling). Most of the topics in the early grade mathematics curriculum are structured and presented well, but there is a problem of alignment of contents in the curricular materials. In addition to that, contents under the topics; fraction, measurement and geometry are not logically organized to the extent possible, and their sequence and structure are not appropriate according to the nature of mathematics, children prerequisite knowledge, and individual, social, and cultural conditions. Moreover, gaps were observed in sequencing concepts logically under the topics; introducing numbers 21-100, operations on numbers 21-100 in the curriculum. This is an indication of the problem in connecting concepts under different topics at the level and continuity of contents through topics and grade levels. Hence it implies the need for focusing on the connection and continuity of concepts among topics and grade levels, and appropriateness of contents with the nature of the mathematics and children personal, social, and cultural background when revising the curriculum.

2. Early grade mathematics curriculum lacks adequacy of contents to equip early grade children with the necessary knowledge and skills at the level.

It is expected that learning objectives in a curriculum to be logical and address all cognitive, affective, and psychomotor domains in a balanced and adequate way. However, in the early grade mathematics curriculum the affective domain is not focused as needed rather more focus was given for cognitive and psychomotor domains. In early grade mathematics curriculum, contents are adequately elaborated however, some important concepts are missed and not treated adequately, and some included that could have been otherwise omitted - example inclusion of the abstract learning of fractions at the early grades. Students reasoning skill and application of contents in real life activity have not also get focus in the materials. And the concept of relative position of numbers is not treated in the curriculum even if it is very important concept for children to understand the number concept and its application deeply. In addition, instructional approaches are not adequately explained in the syllabus, but instructional approaches are guides for teachers to perform their teaching of the given contents. 


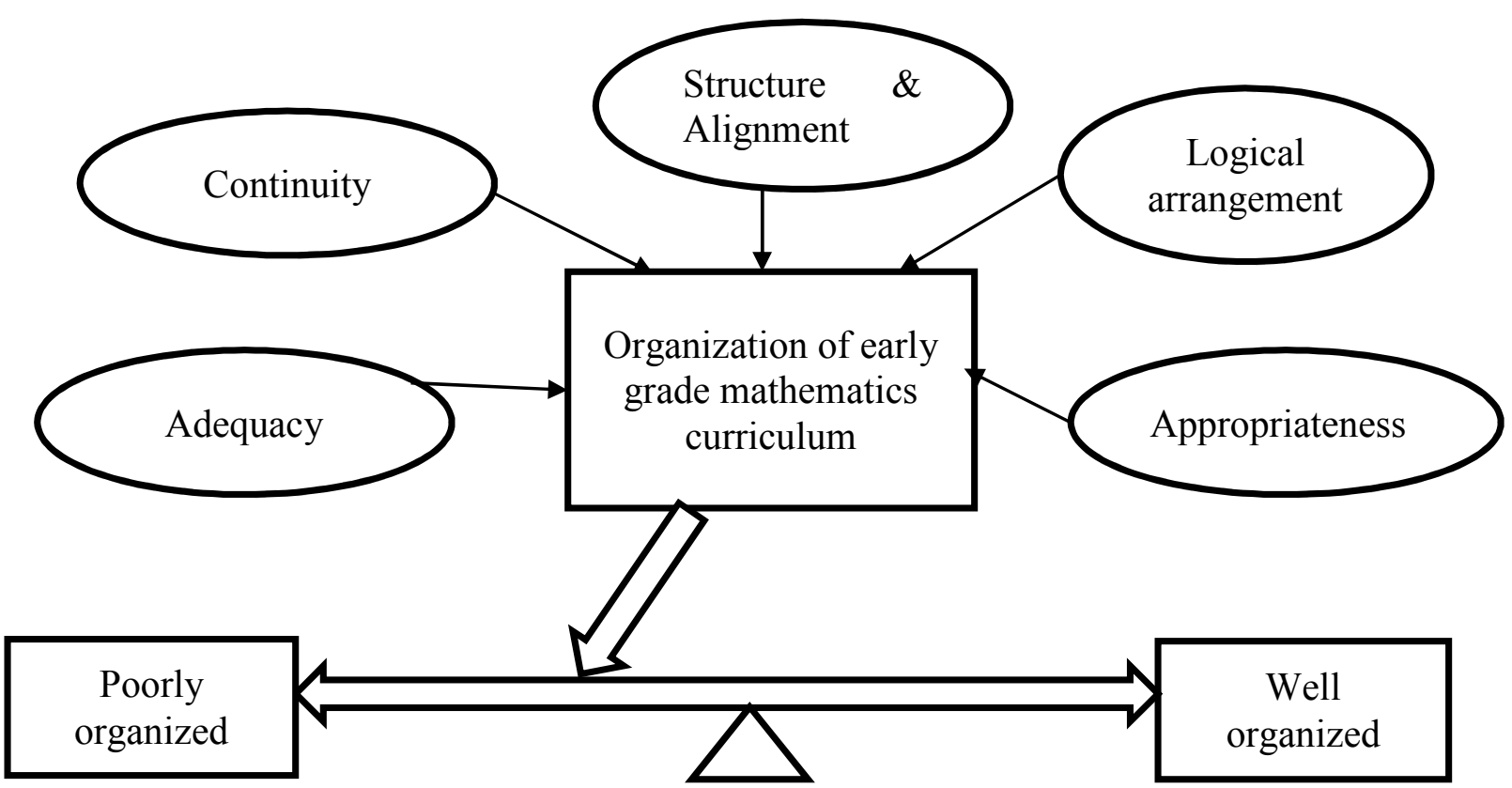

Figure 1: The Position of Early Grade Mathematics Curriculum Organization

\section{Recommendations}

Children learning progression responsive curriculum leads children for more expert understanding in a given concept (Sáez et al., 2013; Wiser et al., 2012). However, Aynalem et al. (2020) in their study on early grade children performance in conceptual and procedural knowledge disclosed that early grade children performance in more conceptual knowledge is poor and they did not perform good in the items that need high cognitive demand. This could be the fact that in early grade mathematics curriculum contents were not organized and presented in a way that they enable the children to have deep understanding of the concepts at the level. This implies the need for considering children learning progression when developing the curriculum. Accordingly, this study suggests the following points to be focused in the process of early grade mathematics curriculum development.

- Appropriateness of contents to the nature of mathematics and children personal, social, and cultural background.

- $\quad$ Logical organization of contents and alignment of curricular materials.

- $\quad$ Adequacy of contents to enable early grade children to have adequate knowledge and skills at the level.

- $\quad$ Linking curriculum with children individual, social, and cultural backgrounds.

More specifically, focus should be given to the alignment of objectives with the aim of teaching mathematics in Ethiopian schools. In addition, children's reasoning skill and application of the concepts of contents, and coherence need to get the required attention. Also, instructional experiences and approaches that can lead the TL process should be adequately elaborated and explained in the syllabus.

Having well documented material that can be used as a basic document in the given subject can help to develop well organized and quality instructional materials, hence, this study further suggests that there should be national mathematics learning progression framework for different level of schools that bases researched evidences and can guide the curriculum developers to design learning progression responsive curriculum for each level of schools.

\section{References}

Abraha, A. (2015). Quality of Primary Education in Ethiopia: the Case of Early Grade Mathematics Competency in Tigrai. Addis Ababa University.

Aggarwal, J. (2009). Principles, methods \& techniques of teaching: Vikas Publishing House.

Aynalem, T., Nigusse, A., \& Kassa, M. (2020). Early Grade Children Procedural and Conceptual Knowledge in Number Pattern Concept at Halaba Developing Country Studies, 10, 12.

Bayissa, D. (2000). Factors Influencing the Implementation of Mathematics Curriculum in General Secondary Schools in East Showa Zone of Oromia Region. Addis Ababa University.

Bermejo, V., Ester, P., \& Morales, I. (2021). A constructivist intervention program for the improvement of mathematical performance based on empiric developmental results (PEIM). Frontiers in Psychology, 11, 3784.

Bristow, S. F., \& Patrick, S. (2014). An International Study in Competency Education: Postcards from Abroad. CompetencyWorks Issue Brief. International Association for K-12 Online Learning. 
Bruner, J. S. (2009). The process of education: Harvard University Press.

Clements, \& Stephan, M. (2004). Measurement in pre-K to grade 2 mathematics. Engaging young children in mathematics: Standards for early childhood mathematics education, 299-317.

Council, N. R. (2007). Taking science to school: Learning and teaching science in grades K-8: National Academies Press.

Duschl, R., Maeng, S., \& Sezen, A. (2011). Learning progressions and teaching sequences: A review and analysis. Studies in Science Education, 47(2), 123-182.

Gagné, R. M., Scriven, M., \& Tyler, R. W. (1969). Perspectives of curriculum evaluation: McNally.

Hashmi, A., Hussain, T., \& Shoaib, A. (2018). Alignment between Mathematics Curriculum and Textbook of Grade VIII in Punjab. Bulletin of Education and Research, 40(1), 57-76.

Hilario, R. R. (2006). Elementary Mathematics Education Curriculum ofJapan and the Philippines. 秋田大学教 育文化学部研究紀要 教育科学, 61, 9-19.

Hunkins, F. P., \& Ornstein, A. C. (2016). Curriculum: Foundations, principles, and issues: Pearson Education.

Hyson, M. (2016). Approaches to Learning: Kindergarten to Grade 3 Guide. Retrieved from.

Initiative, C. C. S. S. (n.d). New York State p-12 common core learning standards for mathematics: Retrieved from file://C:/Users/GreenfeldR/Downloads/nysp12cclsmath. pdf.

Kasimbu, D. M. (2004). The Relationship between the Attitudes towards Mathematics and Achievement in some Selected Schools In Mutomo Sub-District, Kenya.

MoE. (2009). Curriculum Framework for Ethiopian Education (KG-Grade 12) Addis Ababa.

NCTM, P. (2000). standards for school mathematics, Reston, VA. EE. UU.

NEAEA. (2014). Early Grade Mathematics Assessment (EGMA) in Ethiopia: Baseline Study Report. Addis Ababa.

NEAEA. (2016). Ethiopian Fifth National Learning Assessment of Grade Four and Eight Students. . Addis Ababa.

NEAEA. (2018). Ethiopian Second Early Grade Mathematics Learning Assessment (EGMA) Study Report. Addis Ababa.

NEAEA. (2019). Analysis of National Learning Assessment Systems [ANLAS] Ethiopia: Country Report

Okeeffe, L. (2013). A framework for textbook analysis.

Ornstein. (1994). The Textbook-Driven Curriculum. Peabody Journal of Education, 70-85. .

Ornstein, \& Hunkins, P. (1998). Curriculum evaluation. Curriculum: Foundations, principles, and(3rd).

Popham, W. J. (2007). The lowdown on learning progressions. Educational Leadership, 64(7), 83.

Print, M. (1993). Curriculum development and design: Allen \& Unwin.

Rhalmi, M. (2011). Implication of Bruner's learning theory on teaching. Retrieved from myenglishpages. com/articles learningtheories.

Sáez, L., Lai, C.-F., \& Tindal, G. (2013). Learning Progressions: Tools for Assessment and Instruction for All Learners. Technical Report\# 1307. Behavioral Research and Teaching.

Simon, M. A. (1995). Reconstructing mathematics pedagogy from a constructivist perspective. Journal for Research in Mathematics Education, 26(2), 114-145.

Stabback, P. (2016). What Makes a Quality Curriculum? In-Progress Reflection No. 2 on" Current and Critical Issues in Curriculum and Learning". UNESCO International Bureau of Education.

Steele, J. L., Lewis, M. W., Santibanez, L., Faxon-Mills, S., Rudnick, M., Stecher, B. M., \& Hamilton, L. S. (2014). Competency-Based Education in Three Pilot Programs: Examining Implementation and Outcomes: ERIC.

Sunday, A. S., \& Adebowale, A. I. (2013). MATHEMATICS TEXTBOOK ATTRIBUTES AS PREDICTOR OF STUDENTS'ATTITUDE TO MATHEMATICS. European Scientific Journal, 9(9).

Talla, M. (2012). Curriculum development: Perspectives, principles and issues: Pearson Education India.

Taye, M. (2011). Guideline for Preparing and Evaluating Teaching - Learning Materials. Addis Ababa: MoE.

TGE. (1994). Federal Democratic Republic Government of Ethiopia: Education and Training Policy Addis Ababa: ST. GEORGE PRINTING PRESS.

Wilson, M., \& Bertenthal, M. (2005). Systems for state science assessment. Board on Testing and Assessment. Center for Education, National Research Council of the National Academies. Washington, DC: National Academies Press.

Wiser, M., Smith, C. L., \& Doubler, S. (2012). Learning progressions as tools for curriculum development: Lessons from the Inquiry Project Learning progressions in science (pp. 357-403): Brill Sense. 